\title{
On a thickness free expression for the shear modulus of carbon nanotubes
}

Cite as: J. Appl. Phys. 120, 174302 (2016); https://doi.org/10.1063/1.4967229

Submitted: 05 August 2016 . Accepted: 25 October 2016 . Published Online: 07 November 2016

Ghasem Ghadyani, Leila Soufeiani, and Andreas Öchsner
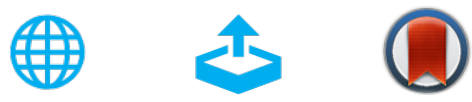

View Online

Export Citation

\section{ARTICLES YOU MAY BE INTERESTED IN}

Porous polymer composite membrane based nanogenerator: A realization of self-powered wireless green energy source for smart electronics applications

Journal of Applied Physics 120, 174501 (2016); https://doi.org/10.1063/1.4966652

Existence of polar switching in the nematic and orthogonal smectic phases in novel four-ring bent-core compounds

Journal of Applied Physics 120, 174101 (2016); https://doi.org/10.1063/1.4966936

Theoretical investigation of the phonon-limited carrier mobility in (001) Si films

Journal of Applied Physics 120, 174301 (2016); https://doi.org/10.1063/1.4966616

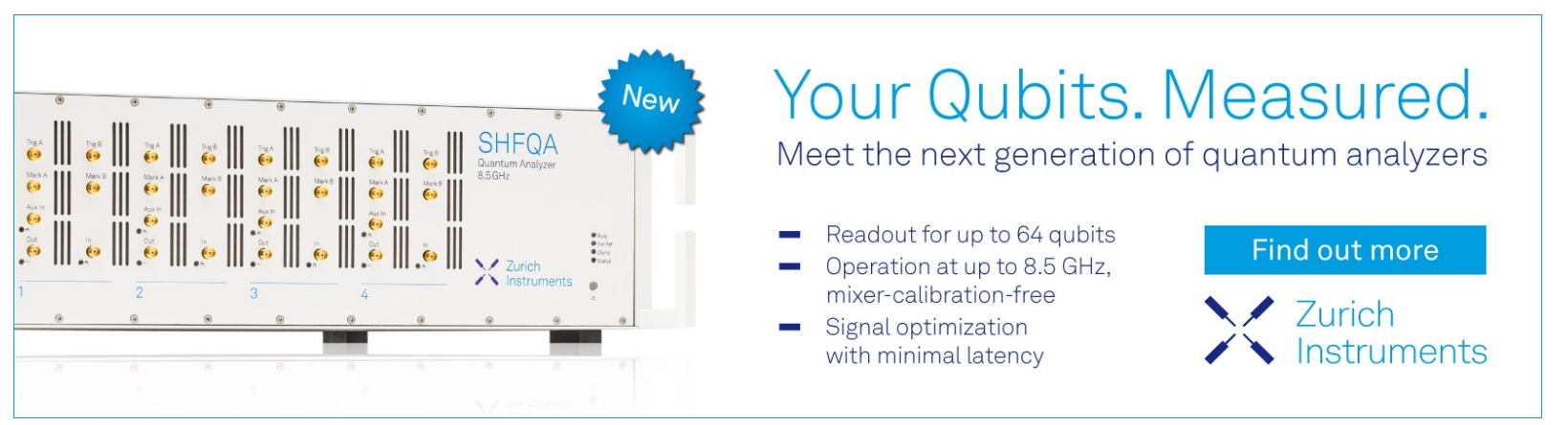




\title{
On a thickness free expression for the shear modulus of carbon nanotubes
}

\author{
Ghasem Ghadyani, ${ }^{1, a)}$ Leila Soufeiani, ${ }^{1, b)}$ and Andreas Öchsner ${ }^{2,3, c)}$ \\ ${ }^{1}$ Department of Mechanical Engineering, University Malaya, 50603 Kuala Lumpur, Malaysia \\ ${ }^{2}$ School of Engineering, Griffith University, Gold Coast Campus, Southport 4222, Australia \\ ${ }^{3}$ School of Engineering, The University of Newcastle, Callaghan, New South Wales 2308, Australia
}

(Received 5 August 2016; accepted 25 October 2016; published online 7 November 2016)

\begin{abstract}
The thickness of carbon nanotubes is an important issue for the characterization and design of these structures. In this article, thickness free expressions for the shear modulus of single-walled carbon nanotubes have been developed by finite element simulations on the minimum potential energy circle. As a part of this work, some equations have been obtained to define the relation between the thickness and the shear modulus, which are in good agreement with previous studies. Moreover, these expressions are in good agreement with both continuum and quantum mechanics and capable to support "Yakobson's paradox," that the scattering data for the elastic properties of carbon nanotubes are due to the not-well-defined thickness for these structures. Furthermore, these expressions can provide a tool for the prediction of the shear modulus of single-walled carbon nanotubes in regards to any thickness assumption when the experimental investigations are too difficult to realize. Published by AIP Publishing. [http://dx.doi.org/10.1063/1.4967229]
\end{abstract}

\section{INTRODUCTION}

There are many empirical and theoretical (i.e., numerical and analytical) investigations using different techniques to study and estimate the mechanical properties of carbon nanotubes. Most of these research values for the stiffness and shear modulus depend on the thickness assumption. In some experimental works, $0.34 \mathrm{~nm}$ has been selected as the thickness, which is the interval between neighboring walls in multiwall carbon nanotubes (MWCNTs). ${ }^{1-4}$ There is some kind of scatter in empirical data mainly because of the tremendously small scales of these structures. On the contrary, in theoretical approaches, there is absolutely less scatter in the values of elastic properties.

In atomistic investigation of SWCNTs, such as the density functional theory, ${ }^{5}$ molecular dynamics simulations, ${ }^{6-15}$ tight-binding model, ${ }^{16,17}$ and $a b$ initio techniques, ${ }^{18,19}$ one can define the product of nanotube thickness $t$ and Young's modulus $E$ as the stiffness $(E t)$ of SWCNTs. Therefore, it is required to assume an effective thickness $(t)$ to define the Young's modulus from these atomistic investigations. Despite unclear thickness values for a SWCNT, many investigators take the thickness of a single graphene sheet $(t=0.34 \mathrm{~nm})$ as the effective thickness. ${ }^{4,8,20-27}$ Nevertheless, a thickness free expression for the stiffness represented by the circumferential stiffness $E_{s}$ is in good agreement among different studies. $^{26}$

Another technique is to simulate SWCNTs as linearelastic thin shells. ${ }^{1,3,13,28-32}$ In this approach, the bending rigidity $\left(\frac{E t^{3}}{\left[12\left(1-v^{2}\right)\right]}\right)$ and tensile rigidity $\left(\frac{E t}{1-v^{2}}\right)$ of SWCNTs are used to obtain the Young's modulus of SWCNTs and the shell thickness $t$ by fitting the atomistic simulation results,

\footnotetext{
a) Author to whom correspondence should be addressed. Electronic mail: g.ghadyani.g@gmail.com. Tel.: +601111605390.

b) soufeiani.leila@gmail.com.

c)andreas.oechsner@gmail.com.
}

where $v$ is the Poisson's ratio. This technique gives the SWCNT thickness $t$ between 0.06 and $0.09 \mathrm{~nm}$, which depends upon the simulation procedures and also the interatomic potential. The thickness evaluation of SWCNTs depends also upon the loading conditions of the SWCNT (e.g., uniaxial tension or bending). In order to define the effect of the wall thickness on the stiffness, a thickness free expression has been derived based on finite element simulations. This expression also supports the Yakobson's paradox, i.e., the scatter of data for the stiffness of SWCNTs. ${ }^{26}$

A thickness free expression for the shear modulus has been derived in this study. Three-dimensional finite element models for zigzag, armchair, and chiral SWCNTs are applied. The chiralities that are considered in this study are $(10,10)$, $(17,0)$, and $(15,4)$, with the same diameter. According to this research, the range of variation of the shear modulus for zigzag, armchair, and chiral configurations is around $0.23 \mathrm{TPa}$ to $3.35 \mathrm{TPa}$.

\section{RESEARCH METHODOLOGY}

\section{A. Single walled carbon nanotube structures}

The most general view of a SWCNT is rolling up a graphene sheet to form a hollow cylinder. A single graphene sheet is rolled along a chiral vector with a specific angle to form a cylinder creating the SWCNTs. The physical structure of a general SWCNT can be described by its diameter $\left(d_{t}\right)$ and chiral angle $(\theta)$ as shown in Fig. 1 . The chiral vector $\overrightarrow{C h}$ is defined by the basis vectors $\left(\vec{a}_{1}\right.$ and $\left.\vec{a}_{2}\right)$ with an angle of $30^{\circ}$ between them

$$
\overrightarrow{C h}=n \vec{a}_{1}+m \vec{a}_{2},
$$

where $n$ and $m$ are integers.

The angle between $\overrightarrow{C h}$ and the zigzag axes $\left(\vec{a}_{1}\right)$ is most commonly known as the chiral angle, $\theta$, and can be computed as follows: ${ }^{33}$ 


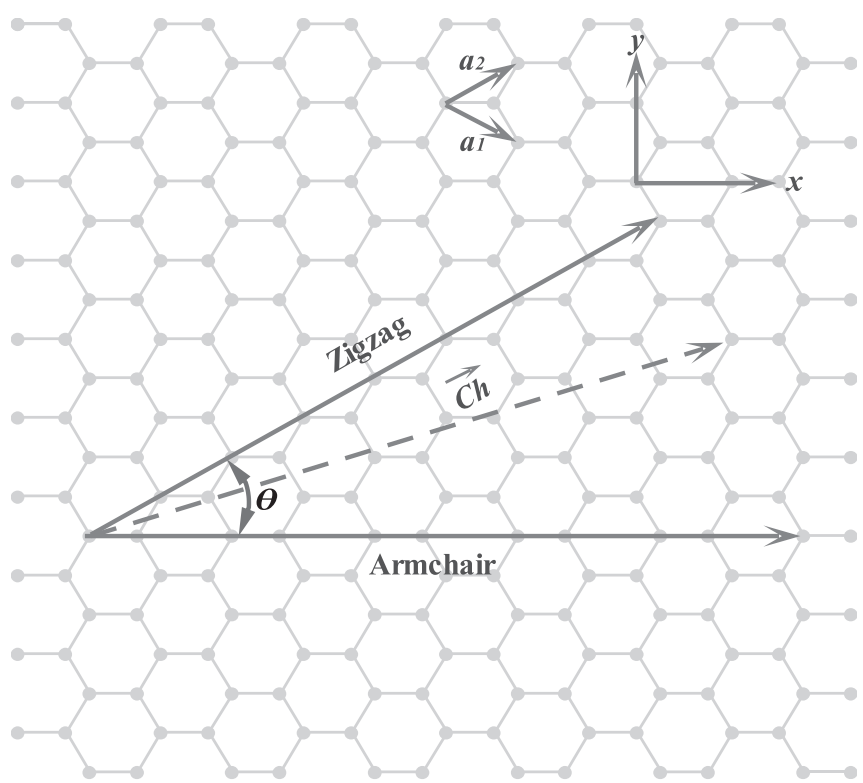

FIG. 1. 2D graphene sheet shown along with the vector which specifies the chiral nanotube and also the lattice vector $\vec{T}$. Cutting plane for both armchair and zigzag clearly shown with rectangle vectors.

$$
\sin (\theta)=\frac{\sqrt{3} m}{2 \sqrt{n^{2}+m^{2}+n m}} .
$$

The length of the chiral vector $(l)$ can be represented by $(n, m)$ and linked to the nanotube diameter $\left(d_{t}\right)$

$$
d_{\mathrm{t}}=\frac{l}{\pi}=\frac{a_{0} \sqrt{m^{2}+m n+n^{2}}}{\pi},
$$

where $a_{0}=\sqrt{3} b$ and $b=0.142 \mathrm{~nm}$ is known as the length of the $\mathrm{C}-\mathrm{C}$ bond.

Respective to the chiral vector and chiral angle of the rolled up single graphene sheet, there are three kinds of carbon nanotubes. In terms of the roll-up vector, the armchair nanotubes are defined by $(n, n)$ and the zigzag nanotubes by $(n, 0)$. For an asymmetric configuration, a chiral angle in the range of $\left(0^{\circ}<\theta<30^{\circ}\right)$ is required. In terms of the chiral vector, the integers $n$ and $m$ are not equal $(m \neq n \neq 0)$ and always $n>m$. Schematic illustrations of the three forms of SWCNTs are shown in Fig. $1 .^{33}$

For any given value of $n$ and $m$, there is a specific number of possible asymmetric chiral structures, which can be derived by the following equations: $:^{24-26}$

$$
\begin{cases}\frac{n+m}{2}-1 & n+m=2 p \\ \frac{n+m}{2}-\frac{1}{2} & n+m=2 p+1,\end{cases}
$$

where $p$ is a positive integer.

\section{B. FE modelling}

In a SWCNT, carbon nuclei are connected together by covalent bonds forming a hexagonal framework. These $\mathrm{C}-\mathrm{C}$ bonds have a specific bond length and bond angle in $3 \mathrm{D}$ space. The displacement of individual atoms under an external force is bound by these bonds. Hence, the total deformation of the SWCNT is the result of the bonds' interactions. In the applied approach, the bonds are modelled as connecting elements and the atom nuclei as the joints of the elements, i.e., SWCNTs are simulated as space-frame structures. By considering the SWCNTs as a space-frame structure, the mechanical properties can be evaluated by the structural mechanics technique. In this current study, 3D finite element models have been used to evaluate the stiffness of SWCNTs. These models are developed using the commercial finite element software MSC.Marc. The Bernoulli beam element with bending, compression, torsion, and tension capabilities, has been used for the current study. Each node has six degrees of freedom: translations in the $x, y$, and $z$-directions and rotations around the $x, y$, and $z$-axes. ${ }^{24-26}$

\section{Elastic properties of beam elements}

In order to evaluate the elastic moduli of the beam elements, a linkage between molecular and continuum mechanics is used. This linkage was originally developed by Odegard et $a .^{34}$ and then by $\mathrm{Li}$ and Chou applied for SWCNT structures. ${ }^{35}$ This approach has been applied in detail by several researchers. ${ }^{22,24-26,36}$ In order to avoid repetition, the detailed description of the approach is mainly omitted in the current work but schematically shown in Fig. 2. This figure shows how the atomic structure of the SWCNTs is simulated as a structural element of a space frame. By assuming a circular cross-sectional area for the element, the simulation leads to the correspondence of the bond length $\mathrm{C}-\mathrm{C}$ with the element length $a_{c c}$ as well as the wall thickness $t$ with the element diameter.

The mechanical stiffness models deliberated above clearly describe a SWCNT structure using beam elements.
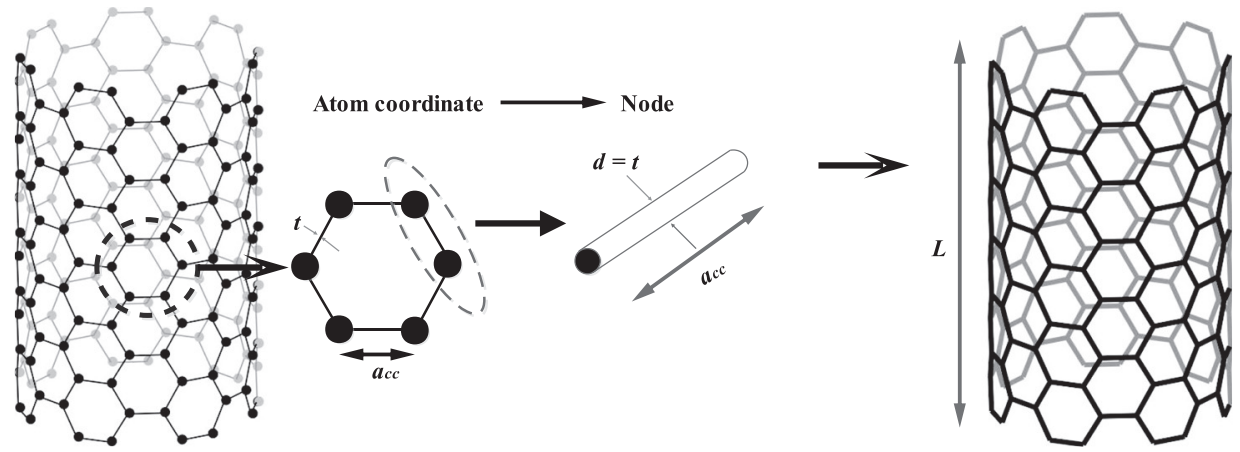

FIG. 2. Linkage between molecular and continuum mechanics. 
Furthermore, the carbon nuclei were represented as nodes at corresponding coordinates. The global coordination of nuclei of the carbon atoms in any model can be found by applying a pure transformation on the associated coordinate in the graphene plane. ${ }^{35,37}$ Consequently, the three-dimensional finite element models relate to different configurations (i.e., zigzag, armchair, and chiral) of the SWCNTs that have been considered in this study. Specific material and mechanical properties of isotropic elastic beams are used as the input to the finite element models, which are presented in Table I. ${ }^{22,36,38}$

The tensile stiffness, the bending rigidity, and the torsional stiffness of the structural model can be obtained in terms of the corresponding force constants in molecular mechanics $k_{r}, k_{\theta}$, and $k_{\varphi} \cdot{ }^{22,35,36}$ These are

$$
\frac{E I}{a_{c c}}=k_{\theta}, \quad \frac{E A}{a_{c c}}=k_{r} \frac{G J}{a_{c c}}=k_{\varphi} .
$$

Constants $k_{r}, k_{\theta}$, and $k_{\varphi}$ are derived based on the investigation of the molecular mechanical force field for simulating the structures of $\mathrm{C}-\mathrm{C}$ bonds. ${ }^{39-41}$ The corresponding force field constants are $k_{r}=651.97 \frac{\mathrm{nN}}{\mathrm{nm}}, k_{\theta}=0.8758 \mathrm{nN} \mathrm{nm} / \mathrm{rad}^{2}$ and $k_{\varphi}=0.2780 \mathrm{nN} \mathrm{nm} / \mathrm{rad}^{2}$.

Figure 3 shows the finite element models of different configurations of carbon nanotubes with boundary condition.

\section{Shear modulus}

To calculate the shear modulus of SWCNTs, the following equation is used in most of the studies: ${ }^{22,35,36}$

$$
G=\frac{T L}{\theta J}
$$

The models are twisted by applying a small angular rotation around the $z$-axis and then, the corresponding reaction torques were obtained as shown in Fig. 2. In Eq. (6), $\theta, T, L$, and $J$ are the twisting angle, the torque, the length, and the polar moment of inertia, respectively. These values are obtained by the following equations: ${ }^{24}$

$$
J_{i}=\int r^{2} d A=2 \pi \int_{R_{C N T}-t}^{R_{C N T}+t} r^{3} d r=\frac{\pi\left(R_{C N T+t}^{4}-R_{C N T-t}^{4}\right)}{2},
$$

where $J_{i}$ are the polar moments of area for the SWCNTs.

TABLE I. Material and geometric properties of C-C covalent bonds. ${ }^{24,25}$

\begin{tabular}{lcc}
\hline \hline FE parameters & Equation & Obtained value \\
\hline Bond length $\left(a_{c c}\right)$ & - & $0.142 \mathrm{~nm}$ \\
Bond diameter $(d)$ & $d_{b=} 4 \sqrt{\frac{k_{\theta}}{k_{r}}}$ & $0.1466 \mathrm{~nm}$ \\
Cross section area & $\frac{\pi d^{2}}{4}$ & $0.0167 \mathrm{~nm}^{2}$ \\
Second Moment of area $\left(I_{x x}=I_{y y}\right)$ & $\frac{\pi d^{2}}{64}$ & $2.2661 \times 10^{5} \mathrm{~nm}^{4}$ \\
Young's modulus & $E=\frac{k_{r}^{2} L}{4 \pi k_{\theta}}$ & $5.484 \times 10^{-6} \frac{\mathrm{N}}{\mathrm{nm}^{2}}$ \\
Shear modulus & $G=\frac{k_{r}^{2} L k_{\varphi}}{8 \pi k_{\theta}^{2}}$ & $8.701 \times 10^{-7} \frac{\mathrm{N}}{\mathrm{nm}^{2}}$ \\
\hline
\end{tabular}

(a)

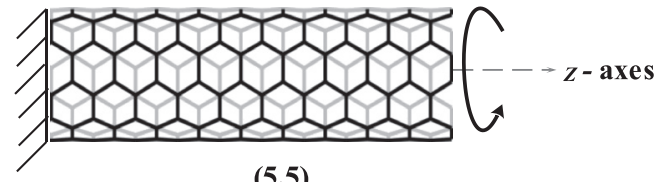

$(5,5)$

(b)

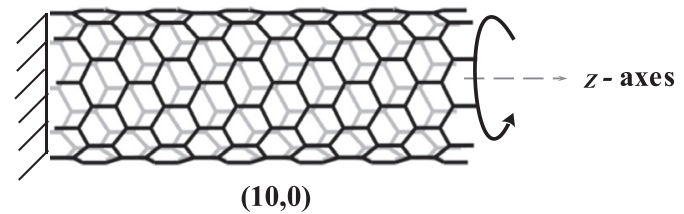

(c)

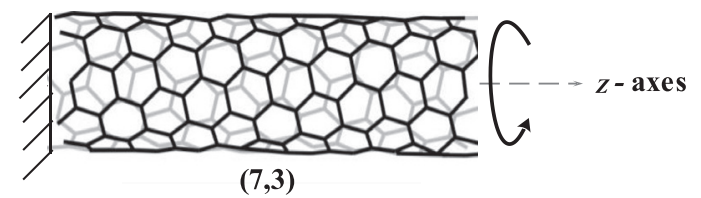

FIG. 3. Finite element models of different configurations of carbon nanotubes with boundary condition: (a) zigzag, (b) chiral, and (c) armchair.

As Eq. (7) shows, this approach cannot be considered for thickness free expressions mainly because the term $J$ depends on the thickness of the structure. In order to calculate a thickness free expression of SWCNTs, the fundamental expression for shear contribution has been used for this study. Furthermore, Fig. 4 clearly shows both approaches to calculate a thickness free expression of the shear modulus

$$
\begin{gathered}
G=\frac{\tau}{\gamma}=\frac{F / A}{\gamma}, \\
F=\frac{T}{R_{C N T}},
\end{gathered}
$$

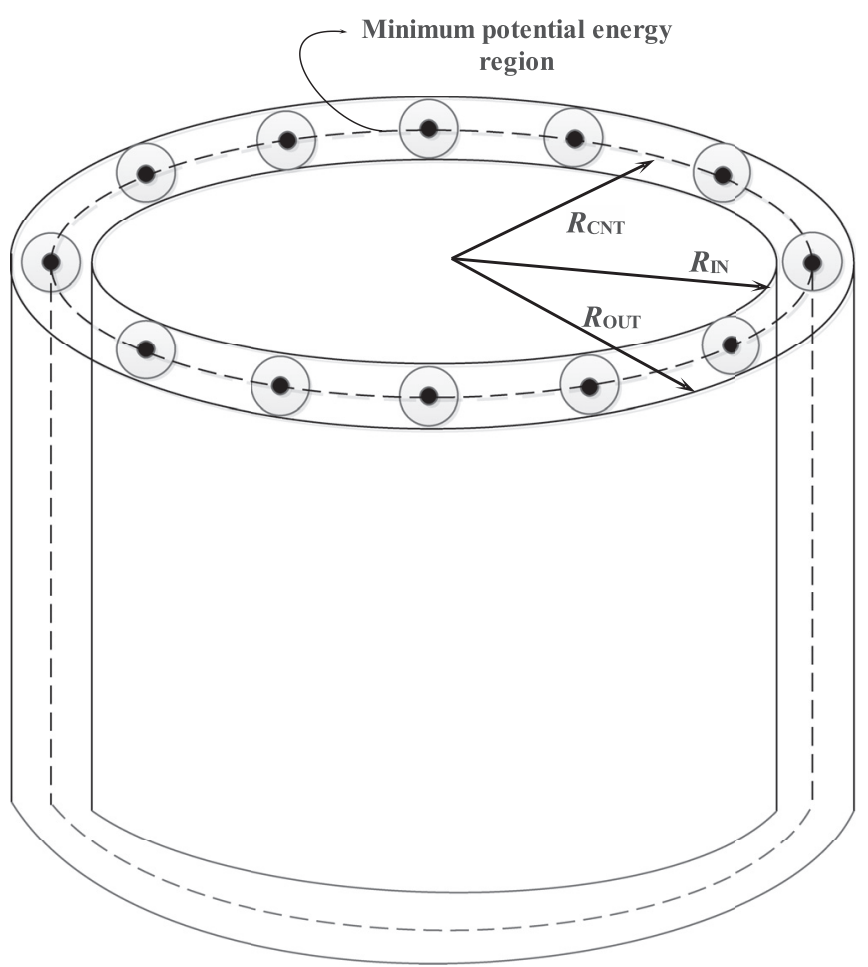

FIG. 4. Thickness free verification of the shear contribution by two approaches. 


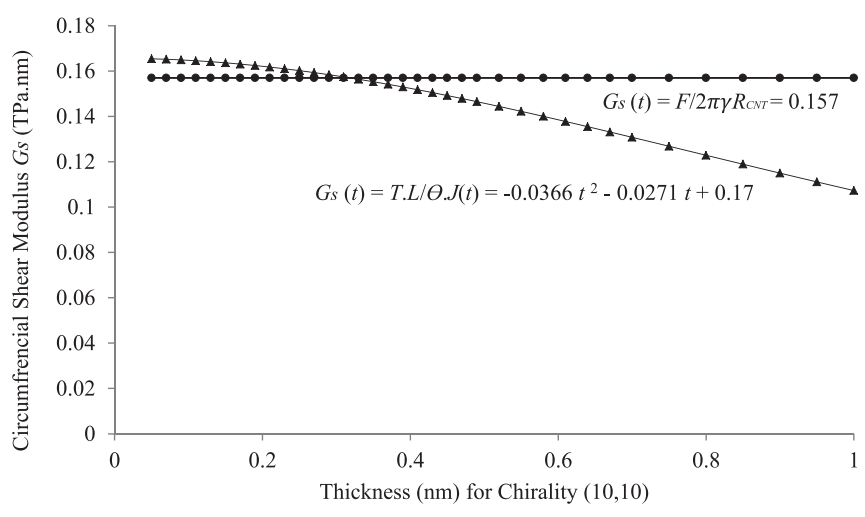

FIG. 5. Cross-sectional equivalence of single walled carbon nanotubes.

$$
\begin{gathered}
A=2 \pi\left(R_{C N T}\right) t, \\
L_{C N T}=2 \pi\left(R_{C N T}\right), \\
G_{s}=\frac{F}{2 \pi \gamma\left(R_{C N T}\right)}, \\
\gamma=\frac{\theta}{L} \times R_{C N T} .
\end{gathered}
$$

In the above equations, $G$ is the shear modulus, $G_{S}$ is the circumferential-specific shear modulus, $L$ is the length of the tube $(15 \mathrm{~nm}), \theta$ is the rotation angle, $R_{C N T}$ is the radius of the tube, and $\tau$ is the shear stress. To obtain the shear stiffness, the reaction angle $(\Theta)$ has been used to obtain the shear strain $\gamma$ by Eq. (13). This reaction resulted from the torque $(T)$ which was applied at one end of the structure.

The length of the average circumference $\left(L_{C N T}\right)$ is shown in Fig. 5.

\section{RESULT AND DISCUSSION}

Table II shows the circumferential-specific shear modulus of the SWCNTs. The shear modulus of SWCNTs is calculated by substitution of any thickness assumption instead of $t$. The coefficients of the equations represent the circumferentialspecific shear modulus $\left(G_{S}\right)$. Figure 6 shows that the shear modulus of all configurations increases with decreasing tube thickness, which is in good agreement with previous studies. $\mathrm{Lu},{ }^{42}$ by using an empirical study, reports $0.483 \mathrm{TPa}$ for the shear modulus of SWCNTs. Molecular mechanics simulations of axial and torsional deformations were employed by Sears and Barta. ${ }^{12}$ They predicted around $0.99 \mathrm{TPa}$ for the shear modulus with $0.134 \mathrm{~nm}$ for the thickness assumption. Chang and $\mathrm{Gao}^{8}$ have predicted $0.15 \mathrm{TPa} \mathrm{nm}$ for the circumferential shear contribution. Natsuki et al., ${ }^{10}$ using molecular dynamics

TABLE II. Circumferential shear modulus and related equations.

\begin{tabular}{lcccc}
\hline \hline Configuration & $G_{\mathrm{s}}(\mathrm{TPanm})$ & $G(\mathrm{~T} \mathrm{~Pa})$ & $R^{2}$ & $R M S E$ \\
\hline Armchair & 0.157 & $\frac{0.157}{t}$ & 1 & 0 \\
Zigzag & 0.161 & $\frac{0.161}{t}$ & 1 & 0 \\
Chiral & 0.159 & $\frac{0.159}{t}$ & 1 & 0 \\
\hline \hline
\end{tabular}

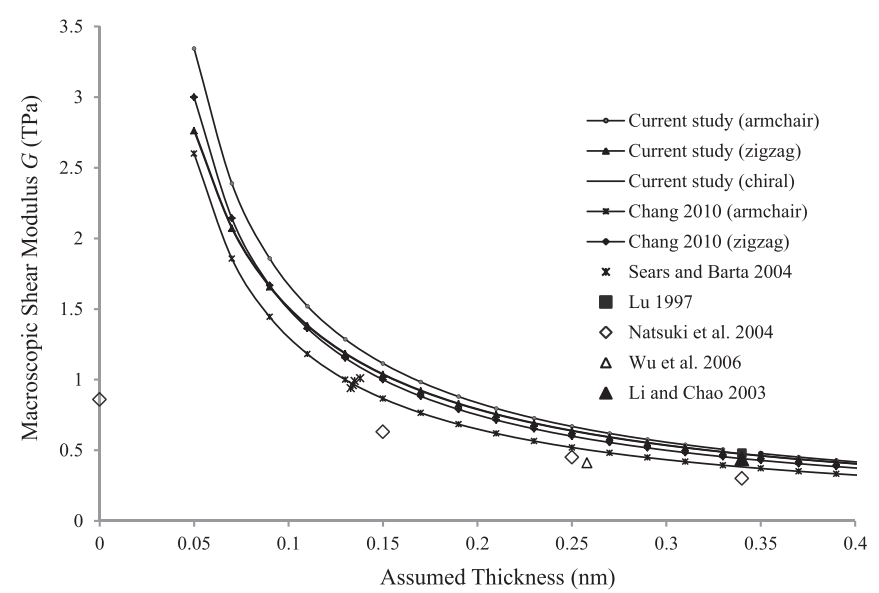

FIG. 6. Thickness dependence of the single-walled carbon nanotubes.

simulation, estimated $0.34 \mathrm{TPa}$ for the shear modulus by taking $0.32 \mathrm{~nm}$ as the thickness assumption. Wu et al., ${ }^{14}$ combining the methods of molecular mechanics and continuum mechanics, predicted $0.412 \mathrm{TPa}$ for the shear modulus. Tserpes and Papanikos $^{22}$ by using the finite element method estimated 0.45 $\mathrm{TPa}$ for the shear modulus. $\mathrm{Li}$ and $\mathrm{Chou}^{35}$ have used a structural mechanics approach to model the deformation of carbon nanotubes. They predicted $0.44 \mathrm{TPa}$ for the shear modulus. Figure 7 illustrates the circumferential shear modulus of both symmetric (i.e., armchair and zigzag) and asymmetric $(5 n, n)$ configurations with respect to the diameter. The range of the circumferential shear modulus that was developed in this study is between $0.125 \mathrm{TPa} \mathrm{nm}$ and $0.165 \mathrm{TPa} \mathrm{nm}$ for all considered configurations. Figure 7 also shows that the shear modulus converged with increasing diameter, which is in good agreement with some previous studies. $9,10,22,35,43$

\section{CONCLUSION}

Based on a linkage between solid mechanics and molecular mechanics, ${ }^{44,45}$ we presented an expression to predict the shear modulus of SWCNTs in regards to the thickness. This study is an extension of a previous study for the stiffness of SWCNTs. ${ }^{26}$ The beauty of this expression is in regards to two points of view. First, this expression is in

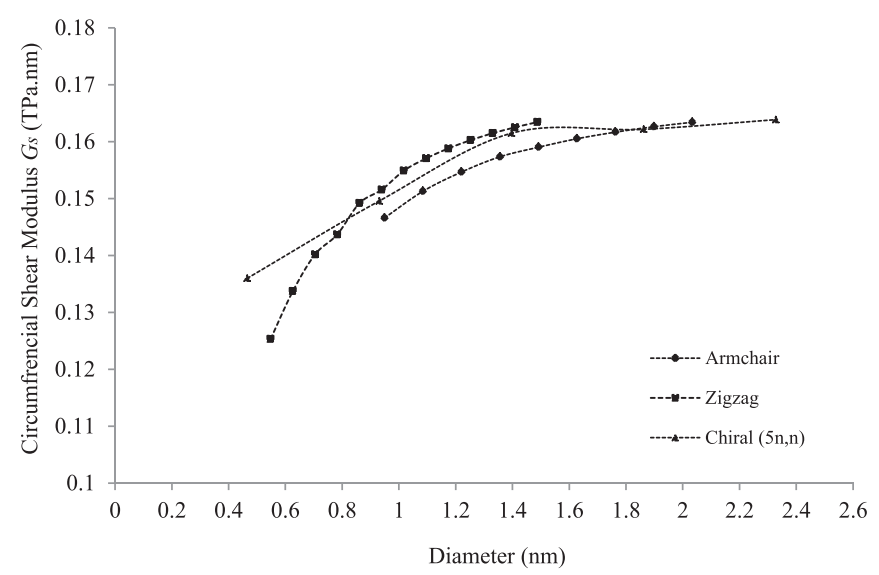

FIG. 7. Variation of circumferential shear modulus of armchair, zigzag, and chiral SWCNTs with tube diameter. 
TABLE III. Comparison of results of our current investigation with the published literature.

\begin{tabular}{|c|c|c|c|c|c|c|c|c|c|c|}
\hline \multirow[b]{2}{*}{ Researchers } & \multirow[b]{2}{*}{ Method } & \multirow[b]{2}{*}{$G(\mathrm{TPa})$} & \multirow[b]{2}{*}{$G_{S}(\mathrm{TPa} n \mathrm{~nm})$} & \multirow[b]{2}{*}{ Thickness (nm) } & \multicolumn{3}{|c|}{ Present Study $G$ (TPa) } & \multicolumn{3}{|c|}{ Present Study $G_{S}(\mathrm{TPa} \mathrm{nm})$} \\
\hline & & & & & $(10,10)$ & $(17,0)$ & $(15,4)$ & $(10,10)$ & $(17,0)$ & $(15,4)$ \\
\hline $\mathrm{Lu}^{4}$ & Experimental & 0.483 & 0.164 & 0.34 & 0.463 & 0.475 & 0.469 & 0.157 & 0.161 & 0.159 \\
\hline Sears and Barta ${ }^{12}$ & Molecular dynamics & 0.99 & 0.133 & 0.134 & 1.248 & 1.236 & 1.242 & 0.157 & 0.161 & 0.159 \\
\hline Chang and $\mathrm{Gao}^{8}$ & Molecular dynamics & 0.457 & 0.155 & 0.34 & 0.463 & 0.475 & 0.469 & 0.157 & 0.161 & 0.159 \\
\hline Natsuki et al. ${ }^{10}$ & Molecular dynamics & $0.86-0.3$ & 0.126 & $0-0.34$ & 0.522 & 0.518 & 0.52 & 0.157 & 0.161 & 0.159 \\
\hline Wu et al. ${ }^{14}$ & Energy-equivalent model & 0.412 & 0.106 & 0.258 & 0.648 & 0.642 & 0.645 & 0.157 & 0.161 & 0.159 \\
\hline Tserpes and Papanikos 22 & Finite element model & 0.45 & 0.153 & 0.147 & 2.43 & 2.42 & 2.38 & 0.157 & 0.161 & 0.159 \\
\hline $\mathrm{Li}$ and $\mathrm{Chou}^{35}$ & Structural mechanics & 0.45 & 0.153 & 0.34 & 0.463 & 0.475 & 0.469 & 0.157 & 0.161 & 0.159 \\
\hline
\end{tabular}

good agreement with both quantum and continuum mechanics. Based on quantum mechanics, different atomic configurations have different electron densities and as a result have a unique thickness. ${ }^{46}$ Moreover, this expression can simply support and explain the well-known "Yakobson's paradox" which refers to the challenging values of the elastic modulus reported in the literature for single-wall CNTs. In this article, we introduced equations for predicting the shear modulus of all configurations (i.e., armchair, zigzag, and chiral) as a function of thickness, which is useful for designing atomic structures of SWCNTs with respect to different assumptions in physical, mechanical, and electrical problems. Although based on nanotube structures, this approach can be easily applied to other atomic structures. Table III shows a comparison of results of our current research with published data.

${ }^{1}$ B. I. Yakobson, C. Brabec, and J. Bernholc, Phys. Rev. Lett. 76, 2511 (1996).

${ }^{2}$ T. Halicioglu, Thin Solid Films 312, 11 (1998).

${ }^{3}$ Z. Xin, Z. Jianjun, and O.-Y. Zhong-Can, Phys. Rev. B 62, 13692 (2000).

${ }^{4}$ J. P. Lu, Phys. Rev. Lett. 79, 1297 (1997).

${ }^{5}$ J. P. Perdew and A. Zunger, Phys. Rev. B 23, 5048 (1981).

${ }^{6}$ J. Cai, R. Bie, X. Tan, and C. Lu, Physica B: Condens. Matter 344, 99 (2004).

${ }^{7}$ D. W. Brenner, Phys. Rev. B 42, 9458 (1990).

${ }^{8}$ T. Chang and H. Gao, J. Mech. Phys. Solids 51, 1059 (2003).

${ }^{9}$ T. Chang, J. Mech. Phys. Solids 58, 1422 (2010).

${ }^{10}$ T. Natsuki, K. Tantrakarn, and M. Endo, Carbon 42, 39 (2004).

${ }^{11}$ Y. Jin and F. Yuan, Compos. Sci. Technol. 63, 1507 (2003).

${ }^{12}$ A. Sears and R. Batra, Phys. Rev. B 69, 235406 (2004).

${ }^{13}$ T. Belytschko, S. Xiao, G. Schatz, and R. Ruoff, Phys. Rev. B 65, 235430 (2002).

${ }^{14}$ Y. Wu, X. Zhang, A. Leung, and W. Zhong, Thin-Walled Struct. 44, 667 (2006).

${ }^{15}$ Y. Huang, J. Wu, and K. Hwang, Phys. Rev. B 74, 245413 (2006).

${ }^{16}$ C. Xu, C. Wang, C. T. Chan, and K. Ho, J. Phys.: Condens. Matter 4, 6047 (1992).

${ }^{17}$ E. Hernandez, C. Goze, P. Bernier, and A. Rubio, Phys. Rev. Lett. 80, 4502 (1998).

${ }^{18}$ G. Van Lier, C. Van Alsenoy, V. Van Doren, and P. Geerlings, Chem. Phys. Lett. 326, 181 (2000).
${ }^{19}$ K. N. Kudin, G. E. Scuseria, and B. I. Yakobson, Phys. Rev. B 64, 235406 (2001).

${ }^{20}$ C. Li and T.-W. Chou, Compos. Sci. Technol. 63, 1517 (2003).

${ }^{21}$ M. Rahmandoust and A. Öchsner, J. Nanosci. Nanotechnol. 12, 8129 (2012).

${ }^{22}$ K. Tserpes and P. Papanikos, Compos. Part B: Eng. 36, 468 (2005).

${ }^{23}$ J. S. Basha and R. Anand, Int. J. Green Energy 8, 332 (2011).

${ }^{24}$ G. Ghadyani, L. Soufeiani, and A. Öchsner, J. Phys. Chem. Solids 89, 62 (2016).

${ }^{25}$ G. Ghadyani and A. Öchsner, Physica E 73, 116-125 (2015).

${ }^{26}$ G. Ghadyani and A. Öchsner, Solid State Commun. 209, 38 (2015).

${ }^{27}$ C. Goze, L. Vaccarini, L. Henrard, P. Bernier, E. Hemandez, and A. Rubio, Synth. Met. 103, 2500 (1999).

${ }^{28}$ Z.-c. Tu and Z.-C. Ou-Yang, Phys. Rev. B 65, 233407 (2002).

${ }^{29}$ A. Pantano, D. M. Parks, and M. C. Boyce, J. Mech. Phys. Solids 52, 789 (2004).

${ }^{30}$ L. Wang, Q. Zheng, J. Z. Liu, and Q. Jiang, Phys. Rev. Lett. 95, 105501 (2005).

${ }^{31}$ C. Ru, J. Appl. Phys. 87, 7227 (2000).

${ }^{32}$ C. Ru, Phys. Rev. B 62, 9973 (2000).

${ }^{33}$ M. Dresselhaus, G. Dresselhaus, and R. Saito, Carbon 33, 883 (1995).

${ }^{34}$ G. M. Odegard, T. S. Gates, L. M. Nicholson, and K. E. Wise, Compos. Sci. Technol. 62, 1869 (2002).

${ }^{35}$ C. Li and T.-W. Chou, Int. J. Solids Struct. 40, 2487 (2003).

${ }^{36}$ A. Kalamkarov, A. Georgiades, S. Rokkam, V. Veedu, and M. GhasemiNejhad, Int. J. Solids Struct. 43, 6832 (2006).

${ }^{37}$ I. László, Carbon 42, 983 (2004).

${ }^{38}$ G. Ghadyani, M. Akbarzade, and A. Öchsner, Key Eng. Mater. 607, 55 (2014).

${ }^{39}$ N. L. Allinger, Y. H. Yuh, and J. H. Lii, J. Am. Chem. Soc. 111, 8551 (1989).

${ }^{40}$ W. D. Cornell, P. Cieplak, C. I. Bayly, I. R. Gould, K. M. Merz, D. M. Ferguson, D. C. Spellmeyer, T. Fox, J. W. Caldwell, and P. A. Kollman, J. Am. Chem. Soc. 117, 5179 (1995).

${ }^{41}$ W. L. Jorgensen and D. L. Severance, J. Am. Chem. Soc. 112, 4768 (1990).

${ }^{42}$ J. P. Lu, J. Phys. Chem. Solids 58, 1649 (1997).

${ }^{43}$ T. Chang, J. Geng, and X. Guo, Proc. R. Soc. A: Math., Phys. Eng. Sci. 462, 2523 (2006).

${ }^{44}$ G. Ghadyani and M. Rahmandoust, Adv. Comput. Nanomech. 99, 99-122 (2015).

${ }^{45}$ W. K. Liu, E. Karpov, S. Zhang, and H. Park, Comput. Methods Appl. Mech. Eng. 193, 1529 (2004).

${ }^{46} \mathrm{~W}$. Heisenberg, The Physical Principles of the Quantum Theory (Courier Dover Publications, 2013). 